\title{
'There's no-one you can trust to talk to here': Churches and internally displaced survivors of sexual violence in Medellín, Colombia
}

\begin{tabular}{|c|c|}
\hline \multicolumn{2}{|c|}{$\begin{array}{l}\text { Authors: } \\
\text { Elisabet Le Roux }{ }^{1} \\
\text { Laura Cadavid Valencia }{ }^{2}\end{array}$} \\
\hline \multicolumn{2}{|c|}{$\begin{array}{l}\text { Affiliations: } \\
{ }^{1} \text { Unit for Religion and } \\
\text { Development Research, } \\
\text { Faculty of Theology, } \\
\text { Stellenbosch University, } \\
\text { Stellenbosch, South Africa }\end{array}$} \\
\hline \multicolumn{2}{|c|}{$\begin{array}{l}{ }^{2} \text { Public servant at the } \\
\text { National Cooperation Agency } \\
\text { of Colombia, Agencia } \\
\text { Nacional de Cooperación } \\
\text { Internacional de Colombia, } \\
\text { APC-Colombia. Lecturer, } \\
\text { Universidad Icesi Cali- } \\
\text { Colombia in graduated } \\
\text { programme psychosocial } \\
\text { intervention }\end{array}$} \\
\hline \multicolumn{2}{|c|}{$\begin{array}{l}\text { Research Project Number: } \\
954361-3\end{array}$} \\
\hline \multicolumn{2}{|c|}{$\begin{array}{l}\text { Description: } \\
\text { Faith communities and sexual } \\
\text { violence survivors within } \\
\text { internally displaced person } \\
\text { (IDP) communities in } \\
\text { Colombia. }\end{array}$} \\
\hline \multicolumn{2}{|c|}{$\begin{array}{l}\text { Corresponding author: } \\
\text { Elisabet Le Roux, } \\
\text { eleroux@sun.ac.za }\end{array}$} \\
\hline $\begin{array}{l}\text { Dates: } \\
\text { Received: } 03 \\
\text { Accepted: } 05 \\
\text { Published: } 17\end{array}$ & $\begin{array}{l}\text { Apr. } 2019 \\
\text { Sept. } 2019 \\
\text { Dec. } 2019\end{array}$ \\
\hline \multicolumn{2}{|c|}{$\begin{array}{l}\text { How to cite this article: } \\
\text { Le Roux, E. \& Cadavid } \\
\text { Valencia, L., 2019, “'There's } \\
\text { no-one you can trust to talk } \\
\text { to here": Churches and } \\
\text { internally displaced survivors } \\
\text { of sexual violence in } \\
\text { Medellín, Colombia', HTS } \\
\text { Teologiese Studies/ } \\
\text { Theological Studies 75(4), } \\
\text { a5491. https://doi.org/ } \\
\text { 10.4102/hts.v75i4.5491 }\end{array}$} \\
\hline Read online: & \\
\hline 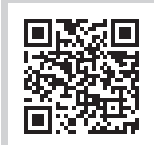 & $\begin{array}{l}\text { Scan this QR } \\
\text { code with your } \\
\text { smart phone or } \\
\text { mobile device } \\
\text { to read online. }\end{array}$ \\
\hline
\end{tabular}

After over 50 years of warfare, Colombia has the largest internally displaced population in the world. Internally displaced women appear to be particularly at risk of sexual violence. Religious belief and affiliation can potentially impact the coping of internally displaced and sexual violence survivors in a country where $79 \%$ of the population self-identifies as Catholic and $13 \%$ as Protestant. This article explores the complex intersect of religion, internal displacement and sexual violence by drawing on interview and focus group data collected from sexual violence survivors and faith leaders in a community of internally displaced survivors in Medellín, Colombia. The qualitative empirical data are used to unpack displaced survivors' experiences and needs, and reflect on churches' response to internally displaced and sexual violence survivors more broadly. We see that by offering a spiritual response to a traumatic event and its consequences, as well as a sense of community and belonging, churches can contribute to the coping ability and healing process of displaced survivors. A theological approach to sexual violence can ensure that sexual violence prevention and response is seen as part of churches' core mandate and mainstreamed in their activities, and by leveraging their ability to influence community and individual beliefs and behaviours, churches can counter the inter-generational cycle of intra-familial violence that so often emerges in the settings of internally displaced persons.

Keywords: sexual violence; internally displaced people; Colombia; Medellin; churches; faith; religion.

\section{Introduction}

When a peace agreement was finally signed between the Colombian government and the Revolutionary Armed Forces of Colombia (FARC) in November 2016, the hope was that it would bring an end to over 50 years of warfare in Colombia. Nevertheless, conflict continues in the country, associated with a blooming industry of narco-trafficking, other guerrillas and armed groups operating nationally and locally, illegal groups controlling neighbourhoods, community violence, intra-familial violence and gender-based violence (GBV) (Gaviria et al. 2016:141). Colombia's protracted conflict has also resulted in the largest internally displaced population in the world: UNHCR in 2018 reported that Colombia has 7.7 million internally displaced persons (IDPs) (Colombia Reports 2018).

The sexual and reproductive rights and health of internally displaced women is generally neglected, despite relevant governmental policies and national legislation (Alzate 2007). Displaced women appear to be particularly at risk of sexual violence. For example, research carried out in 407 municipalities in the presence of an armed actor (public force, guerrilla or paramilitary) found that $17.6 \%$ of the adult female population had been the victim of sexual violence during 2001-2009, but less than 20\% reported it (Meertens 2012:9).

Research has shown that engaging with religion or with their spirituality can help coping amongst sexual violence survivors (Bowland et al. 2011; De la Rosa et al. 2015; Murray-Swank \& Pargament 2005). Religion can also create social cohesion and strengthen the ability to cope with adversity (Berger 1969; Durkheim 1995[1912]). As 79\% of the Colombian population self-identifies as Catholic and $13 \%$ as Protestant (PEW Research Center 2014), it is worth noting the potential influence of religious belief and belonging on those facing challenging circumstances.

Copyright: (C) 2019. The Authors. Licensee: AOSIS. This work is licensed under the Creative Commons Attribution License.

Note: Faith-Based Organisations, sub-edited by Nadine Bowers du Toit (Stellenbosch University), Vhumani Magezi (North-West University) and Elisabet le Roux (Stellenbosch University). 
Thus, whilst religious affiliation does not necessarily indicate active participation in church activities, churches ${ }^{1}$ as a sector of Colombian civil society can nevertheless potentially address sexual violence perpetrated against displaced women. Yet churches are somewhat a 'double-edged sword' (Le Roux et al. 2016:23): Whilst faith leaders have considerable influence on their congregants' beliefs and behaviours, this ability could be used to promote beliefs and behaviours that condone sexual violence and stigmatise survivors. Churches are therefore not necessarily a safe or supportive space for survivors.

This article explores the complex intersect of faith, displacement and sexual violence by drawing on data collected as part of a case study conducted in an IDP community in Medellín, Colombia. The qualitative empirical data are used to unpack displaced survivors' experiences and needs, and how churches are responding to it. In discussing the findings of the study, we reflect on what churches could contribute to address sexual violence in displaced communities.

\section{Internal displacement, sexual violence and churches in Colombia}

The conflict in Colombia started in the 1950s as a two-party warfare between the Liberals and the Conservatives for political dominance. By the 1960s, guerrilla groups entered the fray, and by the 1970s they had the capacity to impose their own rule in several territories. The conflict metamorphosed further when paramilitary groups joined the fighting in the 1980s. These were different regional self-defence groups (legal and illegal) as well as private armies of large landholders and drug lords. Throughout this decades-long conflict, there have been several rounds of peace talks and signed peace agreements, including with guerrilla and paramilitary groups. Unfortunately, all of these have failed to fully end violence in the country, including the most recent 2016 peace agreement between the Colombian government and the FARC (Meertens 2012:S151).

Colombia is a country with the most IDPs in the world, with unidirectional displacement having continued for decades. Internally displaced persons are not the same as refugees. Whilst both are a result of upheaval, refugees have left their countries whereas IDPs stay within their country of origin. According to the United Nations Office for the Coordination of Humanitarian Assistance (UNOCHA 1998), IDPs are defined as follows:

... $[P]$ ersons or groups of persons who have been forced or obliged to flee or to leave their homes or places of habitual residence, in particular as a result of or in order to avoid the effects of armed conflict, situations of generalized violence, violations of human rights or natural or human-made disasters, and who have not crossed an internationally recognized State border. (UNOCHA 2001:1-15)

1. While recognising that the definition of an $F B O$ is a contested topic (Tomalin 2012), for the of an FBO as 'any organisation that derives inspiration and guidance from the of an FBO as 'any organisation that derives inspiration and guidance from the
teachings and principles of the faith or from a particular interpretation or school of thought within the faith'. Churches are therefore FBOs.
Once displaced, most Colombian IDPs stay displaced, and their number simply continues to grow (Shultz et al. 2014:15). Whilst the majority of displacement is from rural to urban areas, intra-urban displacement is also common (Sánchez Mojica 2016). Medellín is one such city where influx of IDPs throughout the conflict, combined with intra-urban displacement, has significantly affected the composition of the city. The rapid arrival of IDPs has led to disorganised and unplanned expansion of the city, including the creation of informal neighbourhoods on mountainsides. These neighbourhoods continue to have only basic service provision and are dangerously over-populated (OcampoGonzález \& Gonzalez-Becerril 2018:122). This coincides with continuous conflict and control of neighbourhoods by illegal armed groups, especially in the urban periphery (Humphrey \& Valverde 2017:163). Paradoxically, Medellín has also received many international awards, lauding its innovation in politics, education and social development (Gaviria et al. 2016:141). Humphrey and Valverde (2017:159), therefore, describe Medellín as a dual city: on the one hand an 'urban miracle', and on the other a 'humanitarian crisis'.

The Colombian government's Unique Victims Registry recognises just over seven and a half million IDPs, of which $51.07 \%$ are female (UNHCR 2018). However, it should be noted that displacement affects men and women differently (Meertens 2012:5-10). With men dying or becoming part of armed groups, displacement forces women to assume new responsibilities as heads of household. Furthermore, displacement usually impacts rural women more harshly than men, as it impacts their life projects ${ }^{2}$ differently. Yet these losses unique to women's experiences are seldom considered or addressed. Women also have different attitudes towards return, yet women's voices are rarely listened to, meaning that women's return is often not voluntary, safe and dignified. Furthermore, women are uniquely at risk of GBV before, during and after displacement. With IDP organisations being dominated by male leadership, they often neglect sexual violence and other issues that disproportionately affect women. This has forced women to form female IDP organisations so that these unique needs, including women's risk of experiencing sexual violence, can be dealt with (Meertens 2012:5-10).

Sexual violence could be a part of violent acts that caused displacement; threats of sexual violence could have been the direct cause of displacement; and sexual violence could be a result of the vulnerability of women during and after displacement (Meertens 2012:9). Conflict combined with the disruption of community and institutional protection structures could lead to increased opportunities of GBV perpetration as well as a lack of justice for survivors (Wirtz et al. 2014:2). Yet, it is important to realise that perpetration of violence is not only by guerrillas, soldiers, and paramilitary forces. Intra-familial violence and intimate partner violence

2.The life project of a person is the full self-actualisation of the person concerned. It takes into account a person's calling in life, their particular circumstances, their takes into account a person's calling in life, their particular circumstances, their
potentialities, and their ambitions, which permit them to set specific goals for potentialities, and their ambitions, which permit them
themselves and then try to attain those goals (Rota 2009). 
(IPV) are also common experiences within Colombian IDP settings. This includes physical, sexual, verbal, emotional and financial violence (Wirtz et al. 2014:7). This household-level violence also shows inter-generational patterns, with women who reported witnessing or experiencing violence as children also experiencing violence as adults (Wirtz et al. 2014:8).

The multifaceted nature of GBV calls for an integrated approach that can deal with the 'full complexity and messiness of real life' (Heise 1998:262). The drivers of violence lie on so many different levels that multi-sectoral, integrated and holistic response is needed. Religion is one dimension of such a holistic response. Religion and religious communities can offer a sense of identity, belonging and emotional support. Religion is recognised for its ability to create a sense of belonging amongst a community of believers, creating social cohesion around common religious rites, rituals and beliefs (Berger 1969:51; Durkheim 1995[1912]:382; Hervieu-Léger 2000:82; Keenan 2002:282-283). Furthermore, in the face of chaotic events and challenges, religion provides social solidarity and the interpretative framework that allows the believer to cope with it (Berger 1969:51; Durkheim 1995[1912]:419). Durkheim (1995[1912]:419; emphasis part of original) argues that a believer is 'a man who is stronger. Within himself, he feels more strength to endure the trials of existence or to overcome them'. Such trials could be challenges not only for IDPs but also for the survivors of sexual violence. Engaging with religion or their spirituality could be a way of active coping by the survivors of sexual violence, as religious and spiritual experiences can strongly (positively or negatively) influence the health and wellness of trauma survivors (Bowland et al. 2011:319; De la Rosa et al. 2015; Murray-Swank \& Pargament 2005). Religion thus has the potential to be an important source and aid of coping for survivors.

Colombian churches have been lauded for their influential efforts in promoting peace-building and reconciliation in the country (Bayer 2013; WCC 2018). This is not an uncommon role to fulfil for churches. With their self-appointed role and responsibility to support people, and with religious texts that could be utilised for political ends, religious communities are well positioned to engage in peace-building. Their grassroots engagement and wide reach maximises their influence, and churches' members expect their churches to influence their worldviews and attitudes (Le Roux 2014:67-68). Local religious communities, such as churches, are often the first responders in disasters (natural or man-made), and could mobilise religious beliefs that promote resilience. As they are locally embedded, they are often able to recognise the core needs of the community affected by disaster (FiddianQasmiyeh \& Ager 2013). With the increasing recognition of the role that religious communities play in the lives of people (Olivier 2016), there is an increasing engagement of governments and development and humanitarian organisations and agencies, such as the United Nations Development Programme and the United States Agency for International Development, with religious actors (Le Roux et al. 2016).
Whilst there is increasing recognition that religious ideology and institutions influence norms and beliefs on gender roles, violence and women's pathways for escaping violence (Heise 2011:vii), the potential of churches are not always fulfilled. This seems to especially be the case in relation to sexual violence. Several studies have shown how churches refuses to address the causes and consequences of sexual violence and violence perpetrated against women (Dobash \& Dobash 1979; Engel 1995; Kaviti 2015; Le Roux 2014; Le Roux \& Bowers-Du Toit 2017; Le Roux et al. 2016). Churches and their leaders could be indifferent to the plight of women and the need to promote gender equality, and reinforce harmful myths or misinformation (often due to they themselves being misinformed or uneducated). They even perpetuate harmful beliefs and practices, being themselves products of a patriarchal context and culture (Clarke \& Jennings 2008; Thomson 2014). This is linked to patriarchal beliefs and attitudes which are at the heart of many religions and religious institutions where the superiority of men and submission of women, as preached by these institutions, is one of the structures through which societal patriarchy is perpetrated and consolidated (Millet 1969:64-75; Walby 1986:68). Forced displacement, in turn, makes these inequalities and marginalisation more acute and visible, particularly through women's vulnerability to sexual violence (Perez 2008):

Forced displacement accentuates the marginalization and invisibility already suffered by these women. Their general vulnerability underscores the patriarchal relationships and structures that configure specific gendered notions and practices that are applied both during wartime and on a daily institutional and organizational basis. (p. 33)

Considering how forced displacement accentuates the harms suffered by women - harms in which many churches play at least an indirect role - it is an important setting for studying the intersect between religion and sexual violence, and churches' response to sexual violence. Thus, this article focuses on churches in communities affected by internal displacement, reflecting on how they affect and respond to the plight of internally displaced women at risk of sexual violence.

\section{Methodology}

In 2016, the Fundación Universitaria Seminario Biblico de Colombia (FUSBC) in Medellín, Colombia, was awarded a grant from the Templeton World Charity Foundation for a study entitled 'Integral missiology and the human flourishing of internally displaced persons in Colombia'. Drawing on an international team of researchers, empirical research was conducted within six IDP communities in Colombia. As part of the broader project, faith leaders from each community were asked questions on sexual violence and churches' response to it. However, a more focused investigation of the issue was included through an in-depth case study conducted in one IDP community in Medellín.

The case study was small and conducted over a short period of time. This was partly because of the resource constraints of 
the research project, but largely a result of the incredible sensitivity of the subject matter.

Furthermore, some of the originally proposed research activities were abandoned because of unforeseen challenges that were the result of the community's fragile nature. ${ }^{3}$

The research participants were recruited by a local practitioner who worked in the IDP community with survivors and with faith groups. Three key informant interviews (KIIs) were conducted with female IDPs who were also sexual violence survivors, as well as a focus group with five female IDPs who were also sexual violence survivors. All these women had participated in churches activities (at different churches within the IDP community) but were not members of churches. The youngest survivor was 18 years old, whilst the oldest was aged 53 years. Three KIIs were conducted with faith leaders from two different churches (one female pastor, one female lay leader and one male pastor). ${ }^{4}$ Two of the faith leaders had worked in the IDP community for 3 years, and the third one for 10 years. All sessions were conducted within 3 days. Interviews lasted between 30 and 45 minutes, whilst the focus group lasted 90 minutes. All sessions were conducted in Spanish and recorded with the permission of participants. It was then transcribed and translated for the purpose of this article.

In order to ensure the safety and anonymity of participants in this research, they are identified as only male or female, and as faith leader or sexual violence survivor. The name of specific IDP community is also not included in this article. Care was taken to ensure that the topics explored in focus groups and interviews would not re-traumatise participants and a trained psychological professional was available in the event that participants required attention following the experience. All participants gave their informed consent prior to participating in the study by completing written permission forms. Along with a written explanation of the research, in order to account for low levels of literacy, the researchers gave participants an oral explanation of the nature and purpose of the study and the participants' rights in relation to the study. The focus group and interviews took place in a safe location where privacy was ensured. Transport was provided to all participants.

The research protocol was approved by the Human Subjects Review Committee of Fuller Theological Seminary in the USA. All translated interview transcripts were coded and analysed using Atlas.ti, drawing on an inductive, thematic approach.

\section{Ethical consideration}

This article followed all ethical standards for a research without direct contact with human or animal subjects.

\footnotetext{
3.More details on these activities and the challenges cannot be included in this article so as to ensure the anonymity of the specific community and that of the participants who took part in the research.

4.The faith leaders that were interviewed did not provide their ages.
}

\section{Findings Increased vulnerability}

Affirming the findings of other studies on Colombian displaced women (e.g. Meertens 2012; Wirtz et al. 2014), the research in the Medellín IDP community revealed that, because of their displacement, women were extremely vulnerable to sexual violence. Participants explained that being internally displaced increased women's risk of experiencing sexual violence, in large part because of extreme poverty. Repeatedly during the interviews and focus group, women's vulnerability to sexual violence was linked to their poverty: Young girls desperate to earn money agree to sexual relationships with older men; women stay in relationships with abusive partners who provide financial support; mothers leave their children unsupervised when they go to work, as they cannot afford child care; and the inadequate housing they can afford rarely provides privacy and safety. See, for example, how one faith leader linked different forms of sexual violence to the root cause of poverty:

'... [T] hat's where we go back to the economic aspect. Many times there are children that are left alone because their mother is working, and that's where the abusers come in to take advantage, how they arrive. There are also girls (who) are exploited ... with their consent. I find out from the girls that I (work with) that they let themselves be touched by older men and all that because they give them things ... But they're minors so they're being abused even if it is with consent. And from others that their fathers might be abusing them because sometimes they say 'yes, it seems he abuses and everything', but the mothers always keep quiet because they have no other way of providing for their families.' (Female pastor)

According to participants there was no real police presence in the community, and therefore little intervention was expected when sexual violence occurred. Illegal armed groups controlling the community also do not want the police to enter the community. Those experiencing violence are thus often forced to weigh the possible benefits of calling the police versus illegal armed groups' anger if police are involved. Many women IDPs become frustrated with their helplessness in these situations:

'I think it's like anger, frustration, rage because of the situation. Impotence that they can't do anything else, and for having to accept a situation because you can't make too much of a fuss in the neighbourhood.' (Male pastor)

Even if violence between intimate partners is reported to the police and restraining orders obtained, this does not appear to prevent future violence. For example, one group participant explained how she was unable to enforce the restraining order against her partner, for the police rarely responded when her partner approached her. Even if police came, they would arrest him only if he hurt her badly enough:

'Because if it's only threats, or maybe a light blow, or fear, then they just tell him to leave or something. But things keep on, they 
keep on, they keep on. Until maybe he kills you and then they might do something. Otherwise, they do nothing.' (Survivor group participant \#5)

Thus, lack of both resources and governmental safety and security infrastructure impact female IDPs' vulnerability to sexual violence. Furthermore, both survivors and faith leaders stated that there was very little government support in the community for either IDPs or sexual violence survivors, despite the many laws and resolutions being passed to ensure support and safety of IDPs. This has been noted in other studies on IDPs in Colombia as well (Albuja \& Ceballos 2010). All the survivors who took part in the study have had many experiences of dealing with endless government bureaucracy to gain financial or food aid and housing, with little to no results:

'About the displacement I can say that I had to go through a lot of red tape to get support, and the aid comes once a year and is never complete ... So I think that it's worse, because you're waiting for that assistance and right at the end they can reduce it or it might not even arrive.' (Survivor group participant \#5)

Control of IDP communities by illegal armed groups further inhibits the development of aid and support structures that could potentially benefit IDPs. The presence of illegal armed groups controlling IDP communities has been noted in several studies on IDPs in Colombia (Alzate 2007; Lemaitre \& Sandvik 2014; Sánchez Mojica 2016). These illegal armed groups discourage activities that bring government representatives (e.g. police) into the community, and also any activities that they perceive as threatening to or potentially inhibiting their control over the community. The research team also experienced this resistance. ${ }^{5}$

However, it is important to note that participants felt that the lack of support is not limited to the government and illegal armed groups. Survivors explained that the community was a place where there is little trust and almost no support amongst community members. Afraid of what will happen to them if they disclose and the perpetrator finds out, survivors rarely tell others. They do not know who they can trust and they also do not believe that any support will be forthcoming:

'So[,] what happens is that there's no support in this community. Legally, there's no support, nor with the government or anything, because there's fear. You're scared to talk. It's better to stay quiet even if you're killed, even if you're displaced, even if what happened to him, happens to you. Because there's no one you can trust to talk to there ... Having to live in a [sic] really tough community, not getting a hand from anyone, not getting guidance from anyone, no support from anyone, we're all adrift.' (Survivor group participant \#2)

Unfortunately, the experiences of interviewed survivors show that this lack of support is present within the household space as well. Family members also disbelieve, ignore and reject survivors. Even more disturbing is the fact that sexual violence even takes place in household space, as discussed in more detail in the next section.

\section{Fear within the family}

According to participants from the IDP community, IPV is very common. For example, one survivor told the story of how her husband almost killed her by shooting her twice; another told of the multiple restraining orders that she had against her partner. With the lack of police intervention, the illegal armed groups controlling the community ironically become authorities to which women can turn for help - as long as the perpetrator is not a member of the illegal armed group. This perception that IPV is very common in IDP community concurs with what is seen in other conflictaffected settings. Whilst still under-researched globally, there is increasing evidence that IPV increases in settings affected by conflict (Horn et al. 2014).

However, what was raised much more often than IPV, and discussed in much more detail, is the violence perpetrated by men in the household against girls (females aged less than 18 years).

Whilst violence against children in internally displaced and other humanitarian settings is an under-researched issue (see Stark \& Landis 2016), we see globally that families are often the site of violence against women and girls (Fulu, Kerr-Wilson \& Lang 2014:25). In the majority of cases discussed by research participants, the perpetrator was a father, stepfather or the mother's male partner. What these cases have in common is that the mother rarely believed her daughter when the girl disclosed the violence. One survivor shared the story of her stepfather's abuse and her mother's response:

'Because I lived with my mother and my stepfather, my stepfather would spy on me while I was having a bath. He would touch me. I was never raped, thank God. But the first thing I did was to tell my mom. I'll never forget the beating she gave me for having told her. And she didn't believe me.' (Survivor group participant \#5)

The disbelief and rejection suffered at the hands of their mothers was the central theme in survivors' discussion of their experiences. This was also what faith leaders were observing in the community. Mothers would refuse to believe their daughters, despite physical evidence to the contrary, some going as far as to evict their daughters from the house. One of the survivors interviewed was only 12 years old when her mother told her to leave. In the case of another survivor, her mother exerted continuous pressure on her to deny what had happened to her, despite the survivor going into severe depression.

Mothers not supporting and rejecting their daughters was specially debilitating for survivors in dealing mentally and emotionally with the violence perpetrated against them. A continuous refrain from the survivor focus group was that this was not the way mothers are supposed to act: mothers are supposed to believe and support their daughters. All the survivors who were rejected by their mothers still crave their support and love: 'Because I 
became very depressed, I even had a psychologist at the school. But it didn't help me much because I needed my mother to support me' (Survivor \#3).

The way their mothers treated them has to led to some of the survivors fearing the way the may treat their own children. One survivor, raped as a child by her mother's partner and then evicted by her mother, now refuses to be in a relationship. She fears that a partner might abuse her daughters, and also how she would react if her daughters tell her about it:

'I don't get a partner because I'm also afraid of what might happen or of putting my daughters through the same thing. I'm afraid that I might throw them out or that they might not tell me.' (Survivor \#2)

The household space has thus become, in general, a space of fear. The interviewed survivors feared for their children, as the displaced community where they lived was very unsafe. They feared leaving their children alone while going out to look for work or food. They feared that their daughters would be raped; they feared that their sons would be corrupted and might become part of illegal armed groups terrorising the community.

\section{Churches responding}

All participants discussed how churches in the community address sexual violence and responds to survivors. All of the survivors who mentioned support from a church were receiving it from the same churches. A non-governmental organisation (NGO) was also affiliated to this church. On closer examination, it was found that the support that survivors received was from the affiliated NGO, and the assistance was counselling from a professional psychologist. The psychologist met survivors individually every 2 weeks and, with some women, also worked with their family members:

'She comes every two weeks and it's a process, because my daughters have already been in therapy with her too ... So she was in a process with the girls, treating the head of the family first, then the girls, and then as a family... But she listens to you when you need it.' (Survivor group participant \#5)

However, survivors stated that it was not only the psychologist's professional counselling that was helpful but also her ability to engage with their religious beliefs. Her ability to integrate their faith and beliefs into the counselling process had been very valuable to some of the survivors, as they had struggled with how to think about God and their faith in relation to the events that had befallen them. One survivor in the focus group explained how the counselling helped her in the aftermath of her 6-year-old daughter's attempted suicide:

'It's helped me greatly, especially to grow close to God. Because at that time I said that what was happening to my girl was His punishment because of my rebelliousness. And (the psychologist) helped me understand that no, that it wasn't God's punishment.' (Survivor group participant \#4)
Connecting survivors with God is actually what the interviewed faith leaders saw as their unique role. They believed that God is the only one that could bring true healing to survivors, and that their role as faith leaders was to assist survivors on their journey of connecting with God and moving past what had happened to them:

'For me, the Word of God properly used in their hearts leads to people being healed, and helps dignify people so they can understand it wasn't their fault. God brings hope that things won't end there, that it will work for good, that everything will work for good and the Word of God brings hope and healing to their lives.' (Female pastor)

Considering that the interviewed faith leaders believed that engaging with God is crucially important in the healing of survivors, it was unexpected when they explained that their two churches were not really engaging with survivors of sexual violence. They gave a number of explanations for why this was the case. First, their churches did not have resources to do so. This they felt was true of churches in general. Providing the needed response and support requires financial means that the faith leaders believe churches are simply not capable of providing. At best, churches could provide opportunities to learn skills that would lead to employment or self-employment, as poverty was central to displacement and a key driver of sexual violence within the community:

'Some of the things we can do is provide workshops to help them make things. For example, like wallets and sandals. And we've helped them, taught them how to make sandals and other things. So they can look out for themselves and sell things.' (Male pastor)

Second, whilst the faith leaders interviewed see themselves and churches as positioned to provide guidance, they do not feel they are adequately trained and skilled to deal with the complexity of psychological support required by survivors of sexual violence. It should be noted that this was also the response of the majority of the faith leaders from the other five IDP communities included in the general study. They feel that the emotional and mental harm caused to survivors was of such an extreme nature that they were not able to counsel and accompany survivors on the road to full healing:

'I wish we had more knowledge, more materials, to be able to do this. Because we always find limitations in certain areas because we aren't professionals. So we focus a lot on the Bible, on counselling through the Bible. But I know that psychology and other things, other areas, could really help this population a lot.' (Male pastor)

The third reason offered by the interviewed faith leaders for why churches were not addressing sexual violence, was their belief that no-one in their congregation was affected by it. For example, one faith leader explained that they (as a congregation) were not working with survivors of sexual violence because none of their members has experienced sexual violence. This was highly unlikely, however, considering the high rate of sexual violence perpetrated 
against internally displaced women and girls in Colombia. Furthermore, research has shown that many survivors are hesitant to disclose their ordeal (Ahrens et al. 2010; Orchowski et al. 2013; Tillman et al. 2010). Thus, there appears to be a (intentional or unintentional) blindness to the lived reality of congregants, and also for churches' role in prevention of sexual violence. One survivor, when asked to describe what churches should be doing about sexual violence, explained that churches have a culture of blindness and silence:

'What should churches do? Well, in my opinion ...: Acknowledge the issue more, treat it more ... look out for people more. Because as a woman I know that there are many people that keep quiet on many things. And they may look physically fine, you manage to smile or something, but in the churches there are many people who are dealing with the same things and nobody sees it and it's hard to put it out there and show it.' (Survivor \#2)

She urged churches to intentionally go beneath the surface of things, creating a culture of disclosure and support, seeking out survivors to assist.

It was clear from the interviews with the three faith leaders that they want to assist IDPs through their churches' ministries. They run sporting programmes for youth, caring groups for senior citizens, programmes for pregnant and nursing mothers, handicraft classes for unemployed women, etc. Thus, they are directly engaged with the needs of their community. Yet, when it comes to sexual violence survivors, there does not appear to be the same direct engagement. Whilst counselling is available if a sexual violence survivor chooses to disclose to a faith leader, little programming exists that target survivors and their needs exclusively. Faith leaders' instinctive response, when asked to discuss what churches could do to support sexual violence survivors, was to identify different types of economic empowerment programmes. This was despite the fact that they also stated that faith leaders' most important role was to connect sexual violence survivors with God. In terms of prevention, one faith leader referred to workshops conducted at the churches on sexual abuses and rights. However, no programme existed that prioritised violence prevention at household level. The faith leaders also did not refer to any teaching carried out in church services on sexual violence or its prevention. Therefore, it appears that in their churches there is little religious or theological engagement with the survivors of sexual violence.

\section{Discussion}

In the findings presented above, two key aspects of the intersect between sexual violence and internal displacement have come to the fore. First, an affirmation of internally displaced women's extreme vulnerability to sexual violence, mainly because of tough economic circumstances they are forced to endure. Poverty, combined with little safety or support offered by government, leaves them in a position of extreme vulnerability, with the result that they can trust no person. Second, the household is revealed as a dangerous place. Girls are at particular risk of abuse from the authoritative male figures within the household and there appears to be little trust or support for them (the daughters) from their mothers. Households where families are supposed to offer a secure place of love and support have become a space of fear and rejection.

What does religion (potentially) contribute to the intersection between sexual violence and internal displacement? To answer this question, it is important to first reflect on what the research participants stated about the role of faith and churches in responding to survivors of sexual violence. Both survivors and faith leaders stated the importance of helping survivors to connect their religious beliefs with what had happened to them. This is a spiritual response that connects the traumatic event and its consequences with God. This is confirmed by other studies that have shown the impact that engaging with religion and spirituality can have on survivors (see Bowland et al. 2011; De la Rosa et al. 2015; Murray-Swank \& Pargament 2005). However, owing to a number of possible reasons (discussed above), this religious/spiritual response is often not offered by the churches and their leaders. This is a serious gap, especially when considering what literature shows us that religion can offer those in need. Religion could be a great source of healing for those who face challenging circumstances, offering an interpretative framework that helps them cope as well as a sense of belonging and community (Berger 1969; Durkheim 1995[1912]). A religious response could potentially offer survivors a unique framework and support structure for dealing with what has happened to them. Yet it is not always easy for faith leaders to provide this.

The faith leaders stated that they were ill-equipped to counsel survivors. This is not a response unique to faith leaders working in IDP communities, as a number of studies conducted in different settings on faith leaders' responses to sexual violence have noted that they feel untrained, unskilled and inadequately prepared to assist survivors of sexual violence (see Bruns et al. 2005; Choi 2015; Moon \& Shim 2010; Petersen 2009). There are also decided risks to such unskilled faith-based counselling (Fouque \& Glachan 2000). This highlights the need for appropriate training of faith leaders, for survivors' need for spiritual engagement emphasises the importance of spiritual engagement with faith leaders.

However, the role of religion at the intersection between sexual violence and internal displacement is not limited to its response to survivors. It can play a role in the prevention of sexual violence, for religious communities can be spaces where members are influenced in terms of their beliefs, attitudes and behaviours. Especially faith leaders can play a central role as key social referents and influencers (Le Roux et al. 2016:31). 
The sexual violence affecting the IDP community studied in this article is noted as a debilitating issue by both survivors and faith leaders participating in the research; however, it appears to be treated as marginal by the churches in the community. With the dearth of infrastructure and government actors, churches' grassroots presence allow them to become frontline actors in speaking out about and against sexual violence and its consequences (Le Roux et al. 2016). Unfortunately, this does not appear to be the case in the IDP community studied in Medellin, at least not when reflecting on the experiences of research participants. For example, nobody could mention any instance of sexual violence being the topic of a sermon or discussed in a church service, and no one could name any church programme assisting sexual violence survivors specifically. Interviewed faith leaders stated their availability to counsel survivors who ask for assistance, but they are not engaging in activities that proactively prevent sexual violence or identify and assist survivors. Part of the reason for this absence could be that many churches and their leaders do not recognise sexual violence as a theological issue. Tombs (2014) argues that many churches' response to sexual violence is exclusively pastoral, but what is needed for churches to fully engage on sexual violence is to see it as a theological concern:

'If sexual violence is seen as only a pastoral concern it is more likely to be treated as separate from the theological heart of the churches and its spiritual concern... By contrast, if the pastoral motivation is integrally linked to a more explicitly theological motivation, and linked more directly to spiritual concerns, it is much more likely to become, and to remain, central to the longterm concern of the churches.' (p. 151)

With a pastoral approach linked to a theological approach, sexual violence is seen, described and recognised as a part of the Christian story. Here we specifically think of engaging with sacred scriptures on gender equality and nonviolence, in a process of rediscovering certain neglected scriptures and reinterpreting certain harmful scriptures. Such a process of theological engagement has proved to be very effective in working with both faith leaders and faith community members on nonviolence and gender equality (Le Roux \& Bartelink 2017; Le Roux \& Palm 2018).

Furthermore, in addressing sexual violence in displaced communities, churches and their leaders should leverage the influence that they have on individuals and families. It appears that the enormity of practical challenges faced by IDPs (poverty, lack of housing, unemployment etc.) tends to dominate churches' responses. It is good that churches are responding to the immediate and practical needs of people. At the same time, they must not lose sight of how they could influence people's behaviours, attitudes and practices (Le Roux et al. 2016). This is especially needed in the household space, which this research has found to be especially toxic in at least some IDP communities. Positive parenting could serve as a buffer against community violence and other negative influences (Knerr \& Cluver 2011:4). Faith leaders' potential influence on norms and behaviours could be harnessed to counter the dominant culture of intra-familial violence, thus assisting in making households safe spaces for women and children. This form of intervention should also focus on helping family members re-establish trust, making families a safe space where secrets can be shared and accepted. Intra-familial violence is a dominant experience in displaced settings in Colombia (Wirtz et al. 2014:7) and the longevity of Colombia's conflict arguably has played a large role in the development of an inter-generational cycle of violence and distrust. By intervening in this space, churches, by creating and maintaining family and community, can counter the feelings of isolation of both displaced and sexual violence survivors. Faith leaders' potential for speaking in these private spaces thus could be harnessed, especially through parenting interventions (Fulu et al. 2014):

'Addressing child abuse, harsh parenting and conduct disorder in children are key goals in and of themselves as well as contributing to the prevention of other forms of violence against women and girls. Parenting interventions aim to stem the cycle of events by which child abuse elevates the societal risk years later for wife abuse, sexual aggression, and heightened violent crime.' (p. 25)

\section{Conclusion}

This case study conducted in an IDP community in Medellín, Colombia, allowed for an exploration of the complex intersect of religion, sexual violence and internal displacement. By reflecting on the experiences and needs of survivors and faith leaders in an IDP community, we found that by focusing on the unique contribution that churches make by virtue of being present at grassroots level and 'of the faith', they could greatly contribute to the prevention of and response to sexual violence. Engaging spiritually offers a unique and needed response to the needs of survivors; embracing sexual violence as a theological issue mobilises churches towards its prevention; and leveraging the influence that churches have on beliefs, behaviour and practices, transforms them into agents countering dominant social norms that normalise sexual violence and lead to mistrust and isolation. As IDP communities lack sufficient and coherent sexual violence prevention and response activities, it is even more important that churches contribute towards sexual violence prevention and response.

\section{Acknowledgements}

Dr Christopher Hays and Neil Kramm helped to manage and support the research process.

\section{Competing interests}

The authors have declared that no competing interest exist.

\section{Author's contributions}

The first author (E.L.R.) contributed to the design of the research protocol and interview guide. She analysed the data, did the literature review and wrote the article. The second 
author (L.C.V.) contributed to the design of research protocol, conducted the interviews and reviewed the first draft of the manuscript.

\section{Funding information}

The project was made possible through the support of a grant from the Templeton World Charity Foundation (TWCF).

\section{Data availability statement}

Data sharing is not possible with this article due to the ethical requirements of the research process.

\section{Disclaimer}

The views and opinions expressed in this article are those of authors and do not necessarily reflect the views of TWCF or the Fundación Universitaria Seminario Bíblico de Colombia (FUSBC).

\section{References}

Ahrens, C.E., Stansell, J. \& Jennings, A., 2010, 'To tell or not to tell: The impact of disclosure on sexual assault survivors' recovery', Violence and Victims 25(5), disclosure on sexual assault survivors' recovery', Vio
$631-648$. https://doi.org/10.1891/0886-6708.25.5.631

Albuja, S. \& Ceballos, M., 2010, 'Urban displacement and migration in Colombia', Forced Migration Review 34, 10-11.

Alzate, M.M., 2007, 'The sexual and reproductive rights of internally displaced women: The embodiment of Colombia's crisis', Disasters 32(1), 131-148. https:// doi.org/10.1111/j.1467-7717.2007.01031.x

Bayer, A.-K., 2013, 'Peace processes in Colombia: International third-party interventions', Journal of Peace, Conflict \& Development 20, 61-80.

Berger, P.L., 1969, The sacred canopy: Elements of a sociological theory of religion, Doubleday \& Company, New York.

Bowland, S., Biswas, B., Kyriakakis, S. \& Edmond., T., 2011, 'Transcending the negative: Spiritual struggles and resilience in older female trauma survivors', Journal of Religion, Spirituality \& Aging 23(4), 318-337. https://doi.org/10.1080/15528030. 2011.592121

Bruns, E., Lewis, C., Kinney, L.M., Rosner, L., Weist, M.D. \& Dantzler, J.A., 2005, 'Clergy members as responders to victims of sexual abuse and assault', Journal of Religion \& Spirituality in Social Work: Social Thought 24(3), 3-19. https://doi.org/10.1300/ J377v24n03_02

Choi, Y.J., 2015, 'Korean American Clergy practices regarding intimate partner violence: Roadblock or support for battered women?' Journal of Family violence: Roadblock or support for battered women?', Journal
Violence 30(3), 293-302. https://doi.org/10.1007/s10896-015-9675-0

Clarke, G. \& Jennings, M., 2008, 'Introduction', in G. Clarke, M. Jennings \& T. Shaw (eds.), Development, civil society and faith-based organizations: Bridging the sacred and the secular, pp. 1-16, Palgrave Macmillan, Basingstoke.

Colombia Reports, 2018, Colombia has highest number of internally displaced people viewed 03 April 2019, from https://colombiareports.com/colombia-has-highestnumber-of-internally-displaced-people/.

De la Rosa, I.A., Barnett-Queen, T., Messick, M. \& Gurrola, M., 2015, 'Spirituality and resilience among Mexican American IPV survivors', Journal of Interpersonal Violence 2016; 31(20), 3332-3351. https://doi.org/10.1177/0886260515584351

Dobash, E.E. \&Dobash, R., 1979, Violence against wives: A case against the patriarchy, Free Press, New York.

Durkheim, E., 1995 [1912], The elementary forms of religious life, New York, Free Press.

Engel, M.P., 1995, 'Historical theology and violence against women: Unearthing a popular tradition of just battery', in C.J. Adams \& M.M. Fortune (eds.), Violence against women and children: A Christian Theological sourcebook, pp. 242-61, Continuum, New York.

Fiddian-Qasmiyeh, E. \& Ager, A., 2013, Local faith communities and the promotion of resilience in humanitarian situations: A scoping study, Joint Learning Initiative on resilience in humanitarian situations: A scoping study, Joint Learr
Faith and Local Communities and RSC Working Paper, Oxford.

Fouque, P. \& Glachan, M., 2000, 'The impact of Christian counselling on survivors of sexual abuse', Counselling Psychology Quarterly 13(2), 201-220. https://do org/10.1080/713658485

Fulu, E., Kerr-Wilson, A. \& Lang, J., 2014, What works to prevent violence against women and girls? Evidence review of interventions to prevent violence against women and girls, Annex F, viewed 03 April 2019, from https://assets.publishing. service.gov.uk/media/57a089a8ed915d3cfd00037c/What_Works_Inception. Report_June_2014_AnnexF_WG23_paper_prevention_interventions.pdf.

Gaviria, S.L., Alarcón, R.D, Espinola, M., Restrepo, D., Lotero, J., Berbesi, D.Y. et al., 2016, 'Socio-demographic patterns of posttraumatic stress disorder in Medellín Colombia and the context of lifetime trauma exposure', Disaster Health 3(4), 139-150. https://doi.org/10.1080/21665044.2016.1263086
Heise, L.L., 1998, 'Violence against women: An integrated, ecological framework' Violence against Women 4(3), 262-290. https://doi.org/10.1177/107780129 8004003002

Heise, L.L., 2011, Working paper: What works to prevent partner violence? An evidence overview, Centre for Gender Violence and Health, London.

Hervieu-Léger, D., 2000, Religion as a chain of memory, transl. S. Lee, Rutgers University Press, New Brunswick, NJ.

Horn, R., Puffer, E.S., Roesch, E. \& Lehmann, H., 2014, 'Women's perceptions of effects of war on intimate partner violence and gender roles in two post-conflict West of war on intimate partner violence and gender roles in two post-conflict West African Countries: Consequences and unexpected opportunitic
Health 8(12), 1-13. https://doi.org/10.1186/1752-1505-8-12

Humphrey, M. \&Valverde, E., 2017, 'A tale of dual cities: The urban miracle and humanitarian crisis maps of Medellín (2002-2015)', Journal of Iberian and Latin American Research 23(2), 159-177. https://doi.org/10.1080/13260219.2017.1 365927

Kaviti, L.K., 2015, 'Impact of the Tamar communication strategy on sexual genderbased violence in eastern Africa', International Journal of Humanities and Cultural Studies 2(3), 492-514.

Keenan, W., 2002, 'Post-secular sociology: Effusions of religion in late modern settings', European Journal of Social Theory 5(2), 279-290. https://doi.org/ $10.1177 / 13684310222225450$

Knerr, W. \& Cluver, L., 2011, Parenting and the prevention of child maltreatment in low- and middle-income countries: A systematic review of interventions and a discussion of prevention of the risks of future violent behaviour among boys, viewed 03 April 2019, from http://www.svri.org/sites/default/files/attachments/ 2016-04-13/parenting.pdf.

Lemaitre, J. \& Sandvik, K.B., 2014, 'Beyond sexual violence in transitional justice: Political insecurity as a gendered harm, Feminist Legal Studies 22(3), 243-261. Political insecurity as a gendered harm, Femin
https://doi.org/10.1007/s10691-014-9274-0

Le Roux, E., 2014, 'The role of African Christian churches in dealing with sexual violence against women: The case of the Democratic Republic of Congo, Rwanda and Liberia', Doctoral dissertation, University of Stellenbosch, Stellenbosch.

Le Roux, E. \& Bartelink, B.E., 2017, No more 'harmful traditional practices': Working effectively with faith leaders, viewed 03 April 2019, from https://jliflc.com/wp/ wp-content/uploads/2017/11/HTP-report-final-draft.pdf.

Le Roux, E. \& Bowers-Du Toit, N., 2017, 'Men and women in partnership: Mobilizing faith communities to address gender-based violence', Diaconia 8(1), 23-37.

Le Roux, E., Kramm, N., Scott, N., Sandilands, M., Loots, L., Olivier, J. et al., 2016, 'Getting dirty: Working with faith leaders to prevent and respond to gender-based 'violence', The Review of Faith \& International Affairs 14(3), 22-35. https://doi.org/ violence', The Review of Faith \& Intern
$10.1080 / 15570274.2016 .1215837$

Le Roux, E. \& Palm, S., 2018, What lies beneath? Tackling the roots of religious resistance to ending child marriage, viewed 03 April 2019, from https://www. girlsnotbrides.org/wp-content/uploads/2018/11/FINAL-Religious-leaders-reportHigh-Res.pdf.

Meertens, D., 2012, Forced displacement and gender justice in Colombia. Between disproportional effects of violence and historical injustice, Brookings-LSE Project on Internal Displacement, viewed 03 April 2019, from https://www.ictj.org/ publication/forced-displacement-and-gender-justice-colombia-betweendisproportional-effects-violence.

Millett, K., 1969, Sexual Politics, New York, Ballantine Books.

Moon, S.S. \& Shim, W.S., 2010, 'Bridging Pastoral counseling and social work practice: An exploratory study of Pastors' perceptions of and responses to intimate partner violence', Journal of Religion \& Spirituality in Social Work: Social Thought 29(2), 124-142. https://doi.org/10.1080/15426431003708253

Murray-Swank, N.A. \& Pargament, K.I., 2005, 'God, where are you? Evaluating a spiritually-integrat \& Religion \& Culture 8(3), 191-203. https://doi.org/10.1080/13694670500138866

Ocampo-González, M. \& Gonzalez-Becerril, J.G., 2018, 'Key drivers of migration due to violence in urban areas: A case of Medellín, Colombia', Papeles de Población 24(96), 119-156. https://doi.org/10.22185/24487147.2018.96.17

Olivier, J., 2016, 'Hoist by our own petard: Backing slowly out of religion and development advocacy', HTS Theological Studies 72(4), 1-11. https://doi. org/10.4102/hts.v72i4.3564

Orchowski, L.M., Untied, A.S., Gidycz, C.A., 2013, 'Social reactions to disclosure of sexual victimization and adjustment among survivors of sexual assault', Journal of Interpersonal Violence 28(10), 2005-2023. https://doi.org/10.1177/ 0886260512471085

Pérez, F.E.O. \& Breña, M.O., 2008, 'Forced Displacement among Rural Women in Colombia', Latin American Perspectives 163(35,6), 29-40. https://doi.org/ in Colombia', Latin American

Petersen, E., 2009, 'Addressing domestic violence: Challenges experienced by Anglican Clergy in the Diocese of Cape Town, South Africa', Social Work \& Christianity 36(4), 449-469.

PEW Research Center, 2014, Religion in Latin America: Widespread change in a historically Catholic region, viewed 17 January 2019, from http://www. pewforum. org/2014/11/13/religion-in-latin-america/.

Rota, M., 2009, 'Case-law of the Inter-American Court of Human Rights: Chronicle for the Year 2008', Revus 9, 129-138.

Sánchez Mojica, B.E., 2016, 'A silenced exodus: Intra-urban displacement in Medellín', in D.J. Cantor \& N. Rodríguez Serna (eds.), The new refugees: Crime and forced displacement in Latin America, pp. 87-108, University of London, London.

Stark, L. \& Landis, D., 2016, 'Violence against children in humanitarian settings: A literature review of population-based approaches', Social Science \& Medicine 152, 125-137. https://doi.org/10.1016/j.socscimed.2016.01.052 
Thomson, J., 2014, 'Local faith actors and protection in complex and insecure environments', Forced Migration Review 48, 5-6.

Tillman, S., Bryant-Davis, T., Smith, K. \& Marks, A., 2010, 'Shattering silence: Exploring barriers to disclosure for African American sexual assault survivors', Trauma, Violence and Abuse 11(2), 59-70.

Tomalin, E., 2012, 'Thinking about faith-based organisations in development: Where have we got to and what next?'Development in Practice 22 (5-6), 689-703. https://doi.org/10.1080/09614524.2012.686600

Tombs, D., 2014, 'Silent no more: Sexual violence in conflict as a challenge to the worldwide church', Acta Theologica 34(2), 147-165. https://doi.org/10.4314/ actat.v34i2.9

UNHCR, 2018, Submission by the United Nations High Commissioner for Refugees for the Office of the High Commissioner for Human Rights' Compilation Report viewed 03 April 2019, from https://www.refworld.org/country,COI,UNHCR,,COL, 5 b082a $484,0 . \mathrm{html}$
UNOCHA, 1998, United Nations Office for the Coordination of Humanitarian Assistance: Guiding principles on internal displacement, viewed 10 January 2014, from http:// www.unocha.org/what-we-do/policy/thematic-areas/displacement.

UNOCHA, 2001, United Nations Office for the Coordination of Humanitarian Assistance: Guiding principles on internal displacement, viewed 12 November 2019, from https://www.unocha.org/sites/dms/Documents/GuidingPrinciplesDispl.pdf.

Walby, S., 1986, Patriarchy at work: Patriarchal and capitalist relations in employment, University of Minnesota Press, Minneapolis, MN.

WCC, 2018, Role of churches in Colombia's peace process raised at Global Christian Forum gathering, viewed 17 January 2019, from https://www.oikoumene.org/en/ press-centre/news/role-of-churches-in-colombias-peace-process-raised-atglobal-christian-forum-gathering.

Wirtz, A.L., Pham, K., Glass, N., Loochkartt, S., Kidane, T., Cuspoca, D. et al., 2014 'Gender-based violence in conflict and displacement: Qualitative findings from displaced women in Colombia', Conflict and Health 8(10), 1-14. https://doi.org/ displaced women in Colomb 